\title{
Formação de Professores para o Ensino de Antropologia no Brasil e
}

\section{na Argentina}

\author{
Amurabi Pereira de Oliveira * \\ Maximiliano Rúa **
}

\section{Resumo}

A Antropologia enquanto ciência passou a ser sistematizada a partir do século XIX, de tal forma que seus primeiros docentes eram autodidatas nessa área de conhecimento, e ainda que seu ensino estivesse restrito inicialmente às formações universitárias, em alguns países houve experiências pontuais também na Educação Básica. Nesse artigo analisamos a formação de professores para o ensino de Antropologia no Brasil e na Argentina, considerando os diversos cenários institucionais e acadêmicos existentes nos dois países, pois, se por um lado na Argentina há um menor número de cursos em comparação com o Brasil, por outro, tais cursos são mais específicos, voltando-se para a formação de professores de Antropologia, ao passo que no Brasil essa formação encontrase dissolvida nos cursos de Ciências Sociais, estando seu ensino alocado na disciplina de Sociologia existente na Educação Básica. Buscamos aqui, portanto, analisar como os cursos de formação de professores para o ensino de Antropologia nas escolas desses dois países lidam com os desafios existentes em seus diferentes contextos institucionais e acadêmicos.

Palavras-chave: Ensino de Antropologia. Formação de Professores de Antropologia. Antropologia e Educação.

\footnotetext{
Doutor em Sociologia pela Universidade Federal de Pernambuco (UFPE), Professor do Departamento de Sociologia e Ciência Política da Universidade Federal de Santa Catarina (UFSC).

** Mestre en Antropología Social pela Universidade de Buenos Aires (UBA). Professor da Faculdade de Filosofía e Letras da Universidade de Buenos Aires (UBA).
} 


\section{Introdução}

Pensar a formação de professores para o ensino de Antropologia nos remete a uma ampla gama de desafios, especialmente no que concerne à realidade latino-americana, marcada por profundas desigualdades socioeconômicas, uma ampla diversidade cultural e um recente processo de redemocratização em muitos países, a partir do qual a Educação e o Professorado passam a ser pensados como importantes elementos em sua consolidação (WEBER, 1996).

No que diz respeito mais especificamente ao ensino de uma disciplina no campo das Ciências Sociais, devemos compreender ainda a necessidade que se coloca em torno de uma reflexão que parte de seus pressupostos epistemológicos, considerando ainda que:

O ensino das ciências sociais é uma tarefa complexa, já que exige à didática a resolução sistemática de uma série de problemas que, embora sejam comuns à educação em todas as disciplinas, no caso das ciências sociais se perceberem mais em sagacidade e evidencia em razão da problemática própria dos conteúdos com que devem trabalhar. Para construir uma didática das ciências sociais e estabelecer o próprio caráter de conhecimento do seu conteúdo é necessário dar respostas explícitas a questões tais como a determinação do status epistemológico das ciências sociais, a possibilidade de integração de diferentes ciências sociais entre si, o valor de verdade ou certeza do conhecimento social, os limites da objetividade ou neutralidade desse conhecimento e sua relação com os valores e com a ação do homem.(CAMILLONI, 2007, p. 25).

Estas são algumas questões desafiadores que se colocam ante à formação dos professores de Antropologia, afora o fato de que essa discussão tem ocupado um lugar residual junto aos Departamentos de Ciências Sociais/Antropologia em muitos países, bem como a própria situação da Educação Básica, especialmente a pública.

É importante esclarecer desde já que o exercício comparativo que buscaremos realizar neste trabalho encontra seus limites dentro das diversas tradições intelectuais postas nos dois países aqui examinados, Brasil e Argentina, tendo em vista que o grau de autonomia que a Antropologia alcança em cada um deles é diferente, seja com relação aos cursos de Ensino Superior, seja com relação a seu lugar no currículo escolar.

Enquanto na Argentina há um espaço solidificado e autônomo para a Antropologia nos cursos universitários, no Brasil ela normalmente surge como um dos troncos que compõem o curso de Ciências Sociais, articulando-se com a Sociologia e a Ciência Política, sendo ainda 
recente e pontual a experiência com cursos de graduação exclusivos em Antropologia, ao passo que o ensino de Antropologia na pós-graduação (mestrado e doutorado) inicia-se ainda no final dos anos de 1960 e atualmente está plenamente consolidado, contando com 22 programas em todo o país.

No que concerne ao ensino na Educação Básica, veremos mais adiante que a situação nos dois países também se diferencia, uma vez que na Argentina, ainda que de forma periférica, a disciplina de Antropologia existe de forma autônoma, já no Brasil apenas a Sociologia tem lugar no currículo escolar de âmbito nacional, a qual deveria incluir conteúdos de Antropologia. Estas e outras questões serão problematizadas no decorrer deste trabalho.

Almejamos neste texto realizar uma reflexão sobre quais são os desafios para a formação de professores de Antropologia na América Latina, partindo da análise comparativa de dois cenários em dois diferentes países: a formação de professores de Antropologia na Argentina e a formação de Professores de Ciências Sociais no Brasil, contextualizando o lugar do ensino dessa ciência na escola em ambos os países e enfocando quais os principais desafios postos em termos de formação inicial nas universidades.

\section{A Formação de Professores de Antropologia como um Desafio para os Cursos de Ciências Sociais no Brasil}

O histórico das Ciências Sociais na escola brasileira normalmente é narrado a partir das primeiras décadas do século passado, quando a Sociologia foi introduzida nos currículos escolares, ainda nos anos de $1920^{\mathrm{i}}$, período no qual não havia agências formadoras na área das Ciências Sociais, de tal modo que os primeiros professores dessa disciplina foram autodidatas nesse campo do conhecimento (MEUCCI, 2011). Todavia, a Sociologia não foi a única disciplina entre as Ciências Sociais que esteve presente no currículo escolar nesse período, pois ainda no começo do século XX emergiram os primeiros Gabinetes de Psicologia e Antropologia Pedagógica junto às chamadas Escolas Normais, que ofertavam cursos em nível secundário voltados para a formação docente, sendo recorrente a existência de disciplinas intituladas de "Antropologia Pedagógica", que em muito se aproximavam de uma chamada "Antropologia Física", distando assim dos paradigmas que se tornaram hegemônicos no campo da Antropologia brasileira (OLIVEIRA, 2013c). Acerca das razões acadêmicas que teriam motivado esse silêncio 
em torno desse período da Antropologia brasileira, Correa (1988, p. 14) levanta a seguinte hipótese:

Não acredito que as razões do esquecimento deste período tão interessante da história de nossa disciplina se devam apenas à descrença no tipo de antropologia que se fazia antes de hoje ou à alegada fragilidade institucional dela naquele momento; penso antes que esse esquecimento deve ser atribuído ao fato de que tentamos buscá-la onde ela não podia estar, num "campo antropológico" ainda em constituição, ao invés de encontrá-la lá onde ela se praticava.

Além desse "esquecimento" envolvendo o período em que a Antropologia se fez presente no currículo de formação de professores (sobretudo professoras), chama a atenção o fato de, ao se pensar a reintrodução das Ciências Sociais na segunda metade do século XX, o movimento estabelecido ter se dado em torno da presença da Sociologia no currículo escolar, o que culminou com sua reintrodução obrigatória em todas as séries do Ensino Médio no Brasil a partir de 2008, sem que houvesse prevalecido uma disciplina escolar demarcando claramente uma continuidade em relação à forma como o conhecimento nessa área se estrutura no Ensino Superior, mais especificamente o desenho que assume nos cursos de formação de professores. Podemos levantar algumas hipóteses para compreendermos este movimento, que foi elaborado pelos agentes envolvidos nesta questão:

a) a partir dos anos de 1980, quando passou a haver uma movimentação mais intensa a respeito do retorno das Ciências Sociais na Educação Básica, mais especificamente no Ensino Médio, a utilização do termo Sociologia teria demarcado uma posição estratégica em termos discursivos, pois, tendo sido uma ciência que ocupara um espaço privilegiado no currículo escolar entre os anos de 1920 e 1940, podia-se afirmar um "retorno" às escolas, portanto, a retomada de um lugar que lhe pertenceria de direito. Por outro lado, se o discurso assumido fosse em torno das Ciências Sociais, tal como estão postas nos cursos superiores, esse mecanismo não poderia ser acionado, pois nesse caso seria a busca por um novo espaço no currículo;

b) tendo em vista o processo de regionalização ocorrido no currículo em período recente, a partir da disciplina de Estudos Sociais, especialmente durante o regime militar, mostravase interessante demarcar uma distância clara com relação a este componente, de tal modo que mesmo uma eventual confusão em termos de nomenclatura deveria ser evitada. $\mathrm{O}$ 
ensino de Sociologia traria assim um caráter mais disciplinar e específico a esta ciência presente no currículo;

c) há que se considerar que a campanha em torno do retorno da Sociologia no currículo escolar foi capitaneada inicialmente pelas entidades profissionais, e não pelas acadêmicas (MORAES, 2011), destacando-se a Federação Nacional dos Sociólogos (FNS). Nesse ponto, vale salientar que a única profissão reconhecida pelo Ministério do Trabalho dentro das Ciências Sociais é a de sociólogo (Lei no 6.888, de 10 de dezembro de 1980), portanto, podemos supor que, considerando suas características, tais entidades teriam interesses próprios mais afinados com a reivindicação disciplinar da Sociologia;

d) no mesmo período em que foi encampada a "campanha pelo retorno da Sociologia" ao currículo escolar, a Antropologia vivenciava outros movimentos, sem o amparo de uma entidade profissional nacional, de tal modo que tais questões acabaram por gravitar em torno da maior entidade acadêmica na área: a Associação Brasileira de Antropologia $(\mathrm{ABA})^{\mathrm{ii}}$. Ademais o campo acadêmico da Antropologia ainda estava em processo de consolidação nesse período, pois até o ano 2000 havia apenas dez programas de pósgraduação na área, dos quais metade possuía curso de mestrado apenas, ou seja, havia outras preocupações prioritárias naquele momento para os agentes envolvidos com a Antropologia brasileira;

e) por muito tempo a Antropologia foi considerada uma "costela" da Sociologia (PEIRANO, 2000), o que foi reforçado pelo fato de haver, ao menos até o final dos anos de 1950, uma incipiente divisão disciplinar (MICELI, 1989), de tal modo que se poderia compreender que, estando presente a Sociologia no currículo escolar, as demais Ciências Sociais (Antropologia e Ciência Política) garantiam também seu espaço na escola.

Estas são apenas algumas hipóteses que não esgotam a questão, mas que nos ajudam a pensar porque há uma disciplina denominada Sociologia no currículo escolar e não Ciências Sociais $^{\mathrm{iii}}$. De forma bastante resumida, podemos afirmar que isso reflete os interesses dos agentes em campo, que, enquanto tais, acabam por elaborar estratégias para tornar sua posição hegemônica (BOURDIEU, 2005). Uma vez que possuem maior capital simbólico em campo, têm a capacidade de "deformar" as regras do jogo, impondo assim seus interesses (BOURDIEU, 2004), bem como as condições objetivas que estavam postas no período em que começa a se desenhar o regresso da Sociologia à escola. 
Apesar dessas questões, a formação em nível de graduação daqueles que se encontram habilitados para lecionar a disciplina Sociologia no currículo escolar, os quais constituem atualmente a minoria do contingente de professores que exercem essa função, passa necessariamente por uma formação em um curso de Ciências Sociais, no qual há uma forte articulação entre a Sociologia, Antropologia e Ciência Política, o que é garantido pelas diretrizes curriculares nacionais de tais cursos (BRASIL, 2001; OLIVEIRA, 2013b), havendo a possibilidade, em alguns casos, de o aluno aprofundar sua formação em uma dessas ciências, ou seja, em muitas escolas encontraremos professores formados em Ciências Sociais com ênfase em Antropologia lecionando Sociologia ${ }^{\text {iv }}$.

Nesses termos, falar do ensino de Antropologia na Educação Básica brasileira é algo que toca necessariamente o ensino de Sociologia no Ensino Médio e a licenciatura em Ciências Sociais no Ensino Superior.

Considerando os dados disponíveis na plataforma e-mec (http://www.emec.mec.gov.br), há atualmente no Brasil 117 cursos presenciais de Ciências Sociais que oferecem a licenciatura, o que pode se dar de inúmeras formas, havendo casos de licenciaturas como cursos separados e outros em que surgem como formação complementar, ou ainda alguns cursos que ofertam a habilitação conjunta da licenciatura e do bacharelado, tendo em vista que ainda há nas Ciências Sociais em curso uma ampla variedade de modelos formativos (HANDFAS, 2009) ${ }^{\mathrm{v}}$. Este número tem crescido exponencialmente nos últimos anos, principalmente após a reintrodução da Sociologia no currículo em nível nacional a partir de 2008.

Historicamente, tais cursos são percebidos como algo menor em relação ao bacharelado (MORAES, 2003), o que é algo recorrente no Brasil, onde os cursos de formação de professores são pensados em relação àqueles que formam pesquisadores, isso dentro de uma leitura dicotomizada entre licenciatura e bacharelado. Entretanto este é um cenário em transformação, pois a questão do Ensino se coloca como algo urgente a ser pensado pelas agências formadoras; isso pode ser percebido pelas sensíveis, porém relevantes, mudanças que vêm ocorrendo no plano acadêmico, como o advento do Grupo de Trabalho Ensino de Sociologia, junto ao Congresso Brasileiro de Sociologia em 2005, e do Grupo Ensinar e Aprender Antropologia em 2014 junto à Reunião Brasileira de Antropologia, do Encontro Nacional sobre o Ensino de Sociologia na Educação Básica desde 2009 e a fundação da Associação Brasileira de Ensino de Ciências 
Sociais em 2012, que promoveu seu primeiro congresso em 2013. Além de atividades periódicas que a Associação Brasileira de Antropologia (ABA) tem promovido sobre o Ensino de Antropologia, tanto na programação de suas reuniões bianuais, quanto em atividades específicas voltadas para essa discussão exclusivamente.

Também nesta seara, destacam-se o crescimento e incremento da pesquisa em nível de pós-graduação sobre a temática do ensino de Sociologia, ainda que a maior parte da produção se concentre em Programas de Educação (HANDFAS, MAÇAIRA, 2014), o que reforça a posição periférica ainda ocupada por esta temática na agenda de pesquisa das Ciências Sociais brasileiras $^{\mathrm{vi}}$, ainda que haja experiências pontuais, como a criação da linha de pesquisa em ensino de Sociologia, junto ao Programa de Pós-Graduação em Ciências Sociais da Universidade Estadual de Londrina, em 2011, e do Mestrado Profissional em Ciências Sociais para o Ensino Médio junto à Fundação Joaquim Nabuco.

Em termos de pós-graduação, dos 27 programas em Antropologia nenhum possui uma linha de pesquisa voltada para o ensino, e poucos realizam alguma interface com a educação (OLIVEIRA, 2015), ainda que em alguns casos haja a presença pontual de pesquisadores que desenvolvem pesquisas na interface entre a Antropologia e a Educação (OLIVEIRA, BOIN, BÚRIGO, 2016). ${ }^{\text {vii }}$

No âmbito especifico do ensino de Antropologia, tem havido alguma mobilização para o fomento dessa discussão, o que tem sido realizado principalmente por meio de fóruns e seminários promovidos pela $\mathrm{ABA}$. Porém em tais espaços a discussão privilegiada encontra-se vinculada ao ensino de Antropologia no Ensino Superior, pois, se a discussão junto à Sociedade Brasileira de Sociologia (SBS) foi fomentada a partir da reintrodução da Sociologia no Ensino Médio, na ABA foi a criação dos cursos de Antropologia que promoveu uma intensa mobilização da comunidade acadêmica em torno da questão do Ensino ${ }^{\text {viii }}$.

Há um cenário, portanto, no qual o campo acadêmico da Antropologia move-se tendencialmente a uma direção que não conflui com o debate acerca do ensino de Ciências Sociais na Educação Básica, ainda que se possa indicar algumas iniciativas pontuais, como a existência do Grupo de Trabalho Aprender e Ensinar Antropologia na programação da $29^{a}$ Reunião Brasileira de Antropologia promovida pela ABA. No que diz respeito às pesquisas realizadas nos Programas de Pós-Graduação em Antropologia, ainda são poucos os trabalhos 
sobre a temática do ensino dessa ciência (RUBIN, 1996; SARTORI, 2010; BARBOSA, 2011), e, em todo o caso, tais trabalhos referem-se exclusivamente ao Ensino Superior.

Tal cenário se reflete, por exemplo, na ausência de doutores em Antropologia na elaboração livros didáticos de Sociologia que concorreram ao primeiro edital do Plano Nacional do Livro Didático (PNLD) em que esta ciência foi inclusa, referente à distribuição de livros para o ano de 2012, em que pese o edital de seleção das obras determinar que seja garantida a presença das três áreas das Ciências Sociais nos livros ${ }^{\text {ix }}$.

Considerando os dois livros selecionados na primeira edição do PNLD, podemos observar que as discussões antropológicas, além de dispensar menor atenção para os autores contemporâneos, restringem-se, ressalvadas algumas exceções, ao conceito de Cultura, o que acaba por estreitar a própria compreensão da Antropologia (OLIVEIRA, 2013a).

Tais questões são provenientes da complexa relação estabelecida entre a Antropologia e a disciplina escolar Sociologia, que exprime, tendo em vista a nomenclatura desta última, uma descontinuidade em relação ao campo acadêmico, haja vista a formação dos profissionais habilitados para a disciplina dar-se prioritariamente em curso de graduação em Ciências Sociais; ao mesmo tempo, revela continuidade, quando se leva em conta os documentos oficiais que vêm norteando a discussão, situação que se agrava ainda mais quando consideramos o atual cenário, no qual a maior parte dos docentes que lecionam esta ciência na Educação Básica não possuem formação no campo das Ciências Sociais (LENNERT, 2012). Considerando-se as especificidades que envolvem o campo da Antropologia e sua prática, isso se torna ainda mais delicado, pois o ensino de Antropologia não se vincula apenas à formação teórica, mas também à formação em campo. Como nos indica Lévi-Strauss (2008, p. 395-396):

Para além da questão dos títulos universitários exigidos para a docência (em geral, doutorado ou trabalho de nível equivalente), ninguém deveria pretender ensinar antropologia sem ter realizado ao menos uma pesquisa considerável de campo. [...] Convém acabar, de uma vez por todas, com a ilusão de que se pode ensinar a antropologia no gabinete, com o auxílio de uma edição completa (mas comumente, uma resumida) do Ramo de outro ou outras compilações. Aos que por ventura invocassem, contra essa cláusula, o caso de especialistas ilustres que jamais foram a campo (afinal, Sir James Frazer respondia aos que lhe faziam essa pergunta: "Deus me livre!"...), lembraremos que Lévy-Bruhl, por exemplo, jamais ocupou uma cadeira de antropologia ou com título equivalente (não existia nenhuma nas universidades francesas em sua época), e sim uma cadeira de filosofia. Nada impede que, no futuro, sejam atribuídas a teóricos puros cadeiras pertencentes a disciplinas vizinhas da antropologia, como história das 
religiões, sociologia comparada ou outras. Mas o ensino da antropologia deve ser reservado às testemunhas. Tal atitude nada tem de audaciosa. Na verdade, é respeitada de fato (embora nem sempre de direito) em todos os países em que a antropologia atingiu certo desenvolvimento. (grifos do autor).

Ou seja, há demandas específicas que devem ser encaradas no processo formativo das licenciaturas em Ciências Sociais para pensarmos o ensino de Antropologia na escola, e estas se encontram assentadas na própria idiossincrasia do conhecimento antropológico, fundamental para o mundo contemporâneo, marcado pela profunda diversidade cultural (MAFRA, 2007).

Estas questões, que implicam uma mudança de perspectiva em relação à formação de professores, especialmente no que tange à percepção dos agentes envolvidos no campo acadêmico da Antropologia no Brasil, dependem, em grande medida, do processo de reconhecimento da Sociologia no currículo escolar enquanto um espaço a ser ocupado efetivamente pelas Ciências Sociais, o que abarca, dentre outras questões: a) o fomento à produção acadêmica voltada para essa reflexão, que possibilite a elaboração de uma discussão em torno de uma didática do ensino de Antropologia; b) a participação mais efetiva de antropólogos na produção de material didático para o ensino dessas ciências na Educação Básica, especialmente nos livros didáticos, tendo em vista a centralidade que eles ainda possuem na escola brasileira; c) a inserção de conteúdos vinculados a esta ciência nos exames admissionais para o Ensino Superior, especialmente o Exame Nacional do Ensino Médio (ENEM).

\section{Presencias e ausências da "Antropologia" no sistema educativo da República Argentina}

No âmbito universitário da República da Argentina, há dez universidades em que os antropólogos são formados; no entanto, apenas três dessas instituições contemplam em seus desenhos curriculares disciplinas voltadas especificamente para o ensino da própria disciplina, outorgando uma titulação que habilita para o exercício da docência: a Faculdade de Ciências Sociais (Universidad Nacional del Centro de la provincia de Buenos Aires - UNICEN) outorga o título de Professor de Antropologia; a Faculdade de Humanidades e Arte (Universidad Nacional de Rosario - UNR) outorga o título de Professor em Antropologia; e, finalmente, a Faculdade de Filosofia e Letras (Universidade de Buenos Aires - UBA), que outorga o título de Professor

do Ensino Médio e Superior em Ciências Antropológicas. É esta última que, desde 1958, inclui em seus desenhos curriculares disciplinas que problematizam o ensino da Antropologia 
além dos claustros acadêmicos. Como compreender a ausência da titulação no resto das Universidades Nacionais?

Repassemos o caminho percorrido na Faculdade de Filosofia e Letras (UBA) a criação do título de Professor do Ensino Médio e Superior em Ciências Antropológicas e as disciplinas ou seja, os conteúdos - que envolvem sua formação.

Desde 1910 e durante seus primeiros 50 anos de existência, a UBA outorgava, em grau de equivalência, os títulos de Doutor em Filosofia e Letras e Professor de Ensino Médio, Normal e Especial. Recentemente, depois de 1950, estabeleceram-se os bacharelados, título que se alcança com a aprovação em todas as disciplinas do plano de estudos da carreira respectiva, dando novas feições à formação docente. Durante a década de 1960, as disciplinas necessárias para obter o título de professor eram quatro: Pedagogia, Psicologia da infância e da adolescência, Didática Geral e Prática de Ensino. É durante o golpe militar de 1976, em decorrência das intervenções que sofre a Universidade de Buenos Aires em suas faculdades, que se modifica o plano de formação de professores da Faculdade de Filosofia e Letras, produzindo-se uma redução no plano de estudos anterior, do qual restaram apenas duas matérias para obtenção do título de professor, a saber: "Didática Geral" e "Didática Especial e Práticas de Ensino", disciplinas que continuam até a atualidade.

Em 1984, criou-se o título de Professor de Ensino Médio, Normal e Especial en Ciências Antropológicas. Em 1985, o Decano Normalizador Rodríguez Bustamante, fazendo uso da Lei de Normalização Universitária de 1983, resolve regulamentar o funcionamento dos cursos de Didática Especial e Prática de Ensino, instituindo para ambos regime anual e incluindo a "aquisição de estratégias e técnicas para a condução grupal e individualizada da aprendizagem (comum para todas as licenciaturas); aquisição de técnicas e recursos especiais para a condução de cada tipo de disciplina (particular para cada licenciatura)". Estabeleceu-se também que a cátedra de "Didática Especial e Prática de la Ensino" estivesse a cargo da "Cátedra de Didática Geral" do Departamento de Ciências da Educação, o que implicava que a formação dos Professores em Ensino Normal e Especial em Ciências Antropológicas ${ }^{\mathrm{x}}$ e, como consequência, a escolha e desenho do currículo que os formaria não seriam levados adiante pelo Departamento de Ciências Antropológicas. 
Com o correr dos anos e o aumento crescente das matrículas, foi necessário repensar a formação dos professores. Aos fins da década de 1990, começou-se a gestar o que viria a ser chamado de "departamentalização" das didáticas específicas ${ }^{\mathrm{xi}}$. A "departamentalização" implicava a migração da "Didática Especial e Prática de Ensino" do Departamento de Ciências da Educação para o Departamento de Antropologia. Se bem que fosse benéfico, o trabalho interdisciplinar confinava a problemática do ensino no interior do Departamento de Antropologia e, mais ainda, frustrava o interesse da comunidade profissional pela formação e a incidência de nossa disciplina mais além dos claustros acadêmicos. Considerando isso centralmente, a formação dos(as) estudantes em investigação vinha à licenciatura como uma titulação a que se inclinavam aqueles(as) estudantes que "não tinham interesse na investigação acadêmica", devido a muitos dos professores a cargo da Didática Especial considerarem ser necessário que o debate sobre a formação dos futuros(as) professores(as) se desse nos respectivos departamentos. Assim, no ano 1997, criou-se uma Comissão Interdepartamental coordenada pelo Departamento de Ciências da Educação e integrada pela professora a cargo da Didática Geral em colaboração com cada um dos(as) professores(as) das Didáticas Específicas. Essa comissão redigiu uma nova regulamentação, a qual estabelece que cada Departamento terá como responsabilidade assumir o desenho dos conteúdos que devem formar o Professor em Ensino Média e Superior em Ciências Antropológicas da Faculdade de Filosofia e Letras (UBA). Em 1996, vinte e dois anos depois de sua criação, concretiza-se a "departamentalização", e o Departamento de Antropologia assume a responsabilidade de formar seus egressos no ensino da própria disciplina. A que se devem estas ausências? Como estas ausências afetaram os programas e desenhos curriculares da Educação Básica e do Ensino Superior?

Repassar o percurso que teve o título de Professor no Ensino Médio e Superior em Ciências Antropológicas nos permite reunir indícios que explicitem o sentido atribuído por nossa própria comunidade à outorga de uma titulação. Se um título tem como objetivo estabelecer um conjunto de incumbências, ou seja, um conjunto de capacidades e práticas cuja atribuição e exercício são facultados ao seu titular, as quais são avaliadas e respaldadas por uma determinada instituição, não obstante o aval de dita instituição, este título só adquire sentido, necessariamente, quando outra instituição compartilha e legitima dito aval. Dessa maneira, os egressos das Universidades/Faculdades devem revalidar essas "capacidades e práticas" no marco de outras instituições, no caso que nos convoca as instituições de formação de Ensino Superior, Médio e/ou 
Fundamental. Dessa maneira, cada instituição outorga "incumbências" aos títulos conferidos aos egressos pelas Faculdades/Universidades, abrindo simultaneamente um processo de negociação, disputas e resistências em torno das "capacidades e práticas" que cada professor tem possibilidades de exercer. Um debate epistemológico, pois define que, quem e como produzir conhecimento, mas principalmente político. A ausência durante vinte e dois anos do Departamento de Ciências Antropológicas no desenho dos conteúdos que seus professores egressos deviam adquirir tem relação com as ausências e presenças de nossa disciplina nos currículos das instituições de Ensino Superior, Médio e/ou Fundamental?

O ensino de conteúdos antropológicos foi pensado exclusivamente para âmbitos acadêmicos e, portanto, somado ao fato de não estar respaldado como um tipo de conhecimento singular, segue reproduzindo as formas clássicas de ensino nas aulas universitárias, as quais não necessariamente se correspondem com "outras" aulas. Recordemos que a "Antropologia" como disciplina a ser ensinada em outros níveis do sistema educativo teve uma presença marginal nos espaços curriculares. Antes da Lei Federal de Educação ${ }^{\text {xii }}$ (LEF), existia em alguns currículos de nível médio da Província de Buenos Aires a matéria Antropologia, no último ciclo do nível. Com a implementação da LFE, os conteúdos básicos comuns recuperaram alguns dos temas centrais desenvolvidos por nossa disciplina, mas dispersos em disciplinas diversas, entremeados a outros conteúdos das ciências sociais, reflexo de alguns erros conceituais que traduziram o desenvolvimento da Antropologia nos limites estreitos da sua fase culturalista e relativista. Em referência a esta situação, Novaro (2005, p. 10) aponta que:

Por outra parte, no tratamento da "diversidade" segue sendo claro seu desconhecimento a nível dos conteúdos; as "outras culturas" se mencionam de forma apressada e desarticulada, não se introduzem elementos comparativos. Nos CBC [Ciclos Básicos Comuns] se seguem supondo a centralidade da "Cultura ocidental", propondo-a como modelo de identificação com relação a qual "o diverso" se define como "o outro". Não se adverte a intenção de aprofundar na sua caracterização, com o qual o preceito do respeito pela diversidade não se baseia nem sequer no conhecimento de quem é o que se respeita. Da mesma maneira, embora na representação geral se fale de conflitos, resistências e transformações de distintas sociedades, de avançar na explicação de temas como "preconceitos, discriminação e negação do outro", nos conteúdos concretos, não terminam de definir-se estas situações, nem de situá-las no contexto maior que as explique.

PERSPECTIVA, Florianópolis, v. 35, n. 1, p. 92-112, jan./mar. 2017 http://www.perspectiva.ufsc.b 
Atualmente, mais especificamente após sancionada a Lei Nacional de Educação ${ }^{\text {xiii }}$, algumas das problemáticas que historicamente foram trabalhadas na Antropologia aparecem no atual cenário educativo em âmbito curricular, institucional e áulico ${ }^{\text {xiv }}$. Não obstante a presença sistemática e específica de nossa disciplina, segue sendo uma conta pendente para a comunidade de antropólogos da República Argentina:

Esta multiplicidade de disciplinas que abordam problemáticas afins a nossa disciplina ao passo que outorga oportunidades implica uma imensa dispersão da especificidade disciplinar. Neste sentido seguimos perguntando-nos pela relevância e significatividade que tem os conteúdos antropológicos para serem ensinados nas escolas no atual contexto: não são os conteúdos e categorias elaboradas por nossa disciplina o suficientemente significativos para que sejam apropriados por crianças e jovens em processo de formação?; não são ademais estes conteúdos os que devem ser incluídos nas licenciaturas, para que não se sigam reproduzindo na aula ideias errôneas acerca de conceitos tais como os de cultura, raça, identidade? Por último, sem esgotar nestes parágrafos a problemática da incumbência da Antropologia nos processos educativos, quiséssemos que estas e novas interrogações formassem parte de todos aqueles que estão interessados em construir uma educação mais justa e democrática. Existe um por que e um para que ensinar antropologia hoje nas escoas, não percamos esse objetivo na formação dos estudantes de nossa carreira. (SINISI; CERLETTI Y RÚA, 2011, p. 96).

Finalmente, nos perguntamos, e a vocês igualmente: como repensar nossas próprias práticas profissionais em relação à formação de professores? Em primeiro lugar, é necessário conhecer e assumir que a formação de professores envolve toda a comunidade acadêmica, quer dizer, todas as disciplinas que conformam a formação dos estudantes, e não apenas as que estão envolvidas diretamente no ensino da Antropologia. Isso implica que a transmissão de nosso marco epistêmico se verifica ao longo de todo o processo formativo. Ao assumir que a construção do conhecimento disciplinar envolve toda a comunidade acadêmica e que este conhecimento disciplinar é desencadeado no fazer profissional, podemos visualizar a implicação política que supõe a presença ou a ausência da Antropologia ${ }^{\mathrm{xv}}$ para além dos claustros universitários:

[...] ao estabelecer nexos entre ambos vemos que o problema do conhecimento, no relativo a como se compartilha e constrói o conhecimento na aula representa uma dimensão central e constitutiva de nossa prática profissional, neste caso, de nossas práticas de ensino. Em consequência, a construção do conhecimento se deixa ver como problemático pelo entrecruzamento de questões de diversas ordens: epistêmicas, posto que remete às formas de investigação e certificação desse conhecimento e de sua organização em una disciplina; metodológicas, dado que se relaciona com as práticas profissionais que se aprende determinado conhecimento; e políticas, já que se selecionam e hierarquizam determinados conhecimentos e não outros, operando-se na prática uma eleição valorativa sobre 
a base de um universo de conhecimentos possíveis. (SINISI; CERELETTI Y RÚA, 2011, p. 98).

É neste sentido que se faz necessário participar, como comunidade política - alguns diriam germinal -, na seleção, classificação e sequenciação dos conhecimentos antropológicos e refletir sobre as consequências de sua formulação em termos de conteúdos no interior dos desenhos curriculares do sistema educativo.

Os "conteúdos" expressam uma prática singular de produção de conhecimento que supõe uma posição epistemológica, metodológica e política no interior de um campo de conhecimento. Mesmo assim, são produto de uma prática situacional, que se detecta em um processo de transmissão, produção e apropriação no contexto de certas relações que os reformulam constantemente ao serem ensinados. Relações que colocam as condições materiais a partir das quais um determinado campo disciplinar é visto pelo conjunto da sociedade. Os conteúdos e sua expressão nas diferentes disciplinas curriculares são objetos simbólicos, recursos culturais disponíveis que sentam as condições materiais a partir das quais os profissionais, neste caso os Professores em Ensino Médio e Superior em Ciências Antropológicas, participam do mundo social, do qual os sistemas educativos primário, médio e superior são parte constitutiva.

\section{Considerações Finais}

Como pudemos perceber, ainda que sejam cenários substancialmente distintos, tanto a formação de professores de Ciências Sociais no Brasil quanto de Antropologia na Argentina estão marcadas pela existência de inúmeros desafios, cujo um dos traços em comuns é a marginalidade que esta temática ocupa em seus respectivos campos acadêmicos, em que pese o fato de que no Brasil a reintrodução em nível nacional da disciplina Sociologia na Educação Básica tem fomentado a discussão, porém ainda é bastante tênue esse debate no campo da Antropologia brasileira.

Interessante notar ainda dois movimentos similares, mas que ocorrem em tempos distintos: na Argentina, a partir dos anos de 1990, ocorre a "departamentalização das didáticas específicas", em meio à qual a discussão sobre o ensino de Antropologia migra para o próprio departamento de Antropologia. Com a reintrodução da Sociologia, isso tem ocorrido no Brasil, 
porém de forma ainda muito tímida; todavia, em boa parte das Universidades Públicas brasileiras as disciplinas que tocam diretamente o ensino de Ciências Sociais ainda se encontram alocadas nas Faculdades de Educação, assim como parte significativa das pesquisas sobre o tema realizadas em nível de pós-graduação, o que parece aprofundar a distância da Antropologia brasileira dessa discussão, afinal a própria aproximação da Antropologia com a Educação ainda é um movimento recente. Como indicou Gusmão em entrevista recente (OLIVEIRA, 2014), os antropólogos normalmente esbarram com o objeto educacional em campo, de tal forma que o próprio campo da Antropologia da Educação no Brasil ainda está em processo de formação.

Também observamos a existência da Antropologia por meio de outras disciplinas no currículo escolar, o que se assemelha ao processo vivenciado pela Sociologia por um longo período, que se iniciou em 1942 e apenas se encerrou em 2008, quando a disciplina volta ao currículo escolar, entretanto a Antropologia no Brasil ainda vivencia essa situação, pois seus conteúdos encontram-se dissolvidos principalmente na Sociologia, porém de forma insuficiente.

$\mathrm{Na}$ Argentina, por outro lado, podemos observar uma invisibilidade que se impõe em âmbito institucional à ciência antropológica no currículo escolar, mas que, ao mesmo tempo, contrastar com o caráter mais claramente disciplinar existente, se compararmos ao Brasil. Mesmo considerando que o debate em torno da Antropologia da Educação encontra-se mais avançado neste país que no Brasil, dentro da ampla gama de questões da qual ele se ocupa o ensino ainda é algo periférico.

Nos dois países observamos a existência de tensões que se estabelecem no processo de seleção dos conteúdos, uma vez que, ao nos referirmos ao campo das Ciências Sociais, inúmeras questões de cunho epistemológico, social, cultural e político se colocam, o que por sua vez se desdobra nos cursos de formação de professores, tanto na Antropologia/Ciências Sociais, no caso brasileiro, quanto nas Ciências Sociais, que tiveram que galgar seu espaço no currículo escolar; na medida em que isso ocorreu por meio da disciplina denominada Sociologia, as demais Ciências Sociais (Antropologia e Ciência Política) precisam ainda encontrar seu lugar nesse espaço. Já na Argentina, a Antropologia possui um caráter mais disciplinar na escola, porém sua presença no currículo se dá de forma mais heterogênea e descontínua.

Em que pese as trajetórias diversas dos dois países no que diz respeito ao desenvolvimento da Universidade e da Educação Básica, bem como dos próprios cursos de graduação em Antropologia e em Ciências Sociais, há questões que parecem transpor as barreiras 
nacionais, como a marginalidade que a temática sobre o Ensino ocupa junto à Antropologia na Argentina e às Ciências Sociais/Antropologia no Brasil, bem como as tensões que emergem na seleção dos conteúdos a serem lecionados no que diz respeito a disciplinas que remetem ao mundo social, do qual os professores fazem parte.

Numa realidade escolar em que os dilemas culturais se tornam cada dia mais relevantes, envolvendo questões como raça, gênero, religião etc., a delimitação de um espaço disciplinar consolidado para a Antropologia nos currículos escolares poderia representar um avanço significativo para as discussões hoje centrais no cotidiano das instituições de ensino, o que demanda também uma revisão dos modelos formativos de professores para aqueles que lecionarão os conteúdos da ciência antropológica nas escola, aqueles que deverão possuir não apenas uma sólida formação teórica nesse campo, mas também deverão ser "testemunhas", nos termos que sugere o Lévi-Strauss.

i
Notas
Para uma melhor análise do histórico da Sociologia no currículo escolar, vide os trabalhos de Moraes (2011) e Oliveira (2013d).
ii Na área das Ciências Sociais, A ABA é a associação científica mais antiga do Brasil, tendo sido fundada oficialmente em 1955, entretanto isso ocorre em seu segundo congresso, que ocorreu em Salvador. Dois anos antes ocorreu a primeira Reunião de Antropologia, no Museu Nacional na cidade do Rio de Janeiro, o que vinha sendo planejado ao menos desde 1948, quando o Ministro da Educação e Saúde designou, por meio de portaria datada de 20 de fevereiro daquele ano, uma comissão integrada por Álvaro Fróes da Fonseca, Edgard Roquette Pinto, Arthur Ramos e Heloisa Alberto Torres, para planejar o "Primeiro Congresso Brasileiro de Antropologia".
iii Não queremos afirmar com isso que a Antropologia não possui nenhum espaço em termos de conteúdos junto à disciplina Sociologia no currículo escolar, mas sim que esse espaço deve ser melhor analisado e problematizado, por compreendermos aqui que se trata de uma presença periférica a que ocorre com esta disciplina por meio da Sociologia no Ensino Médio.
iv Deve-se ressaltar o movimento recente que tem ocorrido no Brasil de criação de bacharelados em Antropologia, o que começa a ocorrer nos anos 2000, todavia estes não habilitam seus egressos para atuarem na Educação Básica, além de haver alguns desses bacharelados que se articulam a partir de outras tradições intelectuais, especialmente com um diálogo entre a Antropologia e a Arqueologia.
$\checkmark$ Não estamos considerando nesse momento os cursos ofertados na modalidade EAD, tendo em vista a maior heterogeneidade nesse conjunto e sua complexidade, o que demandaria uma análise mais detalhada.
${ }^{\text {vi } H a ́ ~ u m a ~ c r e s c e n t e ~ i n c r e m e n t o ~ d e ~ p r o d u c ̧ o ̃ e s ~ r e a l i z a d a s ~ e m ~ p r o g r a m a s ~ d e ~ p o ́ s-g r a d u a c ̧ a ̃ o ~ e m ~ C i e ̂ n c i a s ~ S o c i a i s ~}$ sobre o tema do ensino de Sociologia na Educação Básica, o que aponta tendencialmente para uma reversão desse cenário.
vii Este fato reflete no parco número de trabalhos realizados em Programas de Pós-Graduação em Antropologia dedicados ao tema do Ensino, apenas o trabalho de doutorado de Schweig (2015) dedicou-se exclusivamente ao ensino das Ciências Sociais na Educação Básica em programas dessa área de conhecimento.
viii Encontram-se em funcionamento atualmente no Brasil doze cursos de graduação em Antropologia, todos funcionando em Instituições de Ensino Superior (IES) públicas na modalidade bacharelado. 
ix No edital referente ao ano de 2015, já podemos encontrar uma presença mais efetiva de professores com formação em Antropologia entre os autores de alguns dos livros didáticos de Sociologia selecionados.

${ }^{x}$ Em 1992, uma resolução do Conselho Diretivo solicita à Universidade de Buenos Aires que se substitua a denominação "Professor em Ensino Normal e Especial em Ciências Antropológicas" pela de "Professor em Ensino Médio e Superior em Ciências Antropológicas", em concordância com as modificações que se haviam dado no sistema educativo argentino.

${ }^{x i}$ Recordemos que, desde seus inícios, as matérias Didática Especial e Práticas de Ensino dependiam do Departamento de Ciências da Educação, com uma estrutura de cátedra composta de um professor Titular, dependente do dito departamento, e Adjuntos e/ou Chefes de Trabalhos Práticos (a cargo do ditado pela matéria), que dependiam dos diferentes departamentos (História, Geografia, Filosofia, Artes, Ciências Antropológicas e Letras). A estas equipes se somavam ajudantes egressos das Ciências da Educação, especialistas em Didática com os quais se conformavam pares pedagógicos com os especialistas da disciplina.

xii Em Abril de 1993, sancionou-se a Lei Federal de Educação (Lei no 24.195, 29 de abril de 1993), cuja aplicação produziu mudanças profundas no Sistema Educativo Nacional Argentino. Criou a Educação Inicial: Jardins da Infância (3 a 5 anos de idade), sendo obrigatório o último ano. Incluiu o Jardim Maternal (menores de 3 anos). Educação Geral Básica (EGB): unidade pedagógica integral, organizada em ciclos, obrigatória, com uma duração de 9 anos, a partir dos 6 anos de idade. Educação Polimodal: posterior ao cumprimento da EGB, com duração mínima de 3.

xiii A Lei de Educação Nacional foi sancionada em 14 de dezembro de 2006 e promulgada em 27 de dezembro de 2006. Estabelece que a estrutura do sistema educativo compreende quatro níveis: Inicial, desde os 45 dias até os 5 anos de idade; o Primário, que é obrigatório desde os 6 anos de idade; o Secundário, que consta de 5 ou 6 anos, segundo cada jurisdição o determine, e se divide em dois (2) ciclos: um Ciclo Básico, de caráter comum a todas as orientações e um Ciclo Orientado, de caráter diversificado segundo distintas áreas de conhecimento, do mundo social e do trabalho; o Superior, Universitário e não Universitário.

xiv Nos Institutos de Formação Docente da Província de Buenos Aires, algumas das disciplinas que recuperam problemáticas de corte antropológico e nas que estão habilitados os professores são: Antropologia; Antropologia Filosófica; Antropologia Social e Cultural; Arqueologia Americana e Argentina; Evolução do Pensamento e a Cultura Argentina; Filosofia e Cultura; Folclore; Folclore e Cultura Popular; Folclorologia; História da Cultura; História do Pensamento a Cultura Americana; Integração Cultural; Problemática Tecnológica, etc. Na Cidade de Buenos Aires, as disciplinas que concedem o título de "Professor de Ensino Médio e Superior em Ciências Antropológicas" para sua atuação são: Desenvolvimento de Comunidades; Introdução ao Conhecimento da realidade social; Introdução ao estudo da Cultura e da Sociedade; Metodologia da Investigação; História da Cultura; Patrimônio Natural e Cultural Argentino; Políticas Sociais; Problemáticas Contemporâneas; História da Civilização; Antropologia; Cultura Geral; História da Cultura; Cultura Popular e Meios de Massa; Cultura e Meios de Comunicação; História; Políticas Sociais; Biologia; Biologia e Higiene; etc. 


\section{REFERÊNCIAS}

BARBOSA, T. P. Entre o Fazer e o Ensinar Antropologia: a graduação em ciências sociais no estado de São Paulo. 2011. 140f. Dissertação (Mestrado em Ciências Sociais) - Universidade do Estado de São Paulo, Marília, 2011.

BRASIL. Conselho Nacional de Educação. Câmara de Ensino Superior. Parecer CNE/CES n ${ }^{\circ}$ 492/2001. Diretrizes Curriculares Nacionais dos cursos de Filosofia, História, Geografia, Serviço Social, Comunicação Social, Ciências Sociais, Letras, Biblioteconomia, Arquivologia e Museologia. Diário Oficial [da] República Federativa do Brasil, Poder Executivo, Brasília, DF 9 jul. 2001, Seção 1e, p. 50.

BOURDIEU, P. O Poder Simbólico. Rio de Janeiro: Bertrand Brasil, 2005.

Os Usos Sociais da Ciência. São Paulo: EdUNESP, 2004.

CAMILLIONI, A. R. W. Epistemología de la didáctica de las ciencias sociales. In: AISENBERG, Beatriz; ALDEROQUI, Silvia. (org.) Didáctica de las Ciencias Sociais: aportes y reflexiones. Buenos Aires: Paidós, 2007, p. 25-42.

CORREA, M. A revolução das normalistas. Revista Cadernos de Pesquisa, n. 66, p. 13-24, 1988. São Paulo: Fundação Carlos Chagas, 1988.

HANDFAS, A. A Formação do Professor de Sociologia. In: ; OLIVEIRA, L. F. (org.). A Sociologia vai à escola: história, ensino e docência. Rio de Janeiro: Quartet, 2009.

HANDFAS, A.; MAÇAIRA, J. P. Estado da arte da produção científica sobre o ensino de sociologia na educação básica. BIB. Revista Brasileira de Informação Bibliográfica em Ciências Sociais, v.2, n. 74, 2014, p. 45-61. São Paulo: ANPOCS, 2014.

MAFRA, C. Um mundo sem antropologia. Antropolítica, n. 22, p. 151-168, $1^{\text {o }}$ sem. 2007. Niterói: EdUFF, 2007.

MEUCCI, S. Institucionalização da sociologia no Brasil: primeiros manuais e cursos. São Paulo: Hucitec; Fapesp , 2011.

MICELI, Sergio. Condicionantes do desenvolvimento das ciências sociais. In: MICELI, Sergio (Org.). História das Ciências Sociais no Brasil. v. 1. São Paulo: Vértice/IDESP/FINEP, 1989, p. 72-110. 
MORAES, A. C. Ensino de Sociologia: periodização e campanha pela obrigatoriedade. Cadernos CEDES, v. 31, n. 85, p. 359-382, set./dez. 2011. Campinas: CEDES, 2011.

Licenciatura em ciências sociais e ensino de sociologia: entre o balanço e o relato. Tempo Social, São Paulo, v. 15, n.1, p. 5-20. 2003. Disponível em: $<$ http://www.scielo.br/scielo.php?script=sci_arttext\&pid=S010320702003000100001\&lng=en\&n rm=iso >. Acesso em: 5 abr. 2017.

NOVARO, G. Nacionalismo escolar y migraciones en educación: de las hordas cosmopolitas a los trabajadores competentes. In: DOMÉNECH, E. (Org.). Migraciones contemporáneas y diversidad cultural en la Argentina. Córdoba: Centro de Estudios Avanzados/Universidad Nacional de Córdoba, 2005.

OLIVEIRA, A. A Antropologia no Ensino Médio: uma análise a partir dos livros didáticos. Cadernos de Estudos Sociais, Recife, v. 1 e 2, n. 28, p. 1-25, 2013a. Disponível em: <http://periodicos.fundaj.gov.br/index.php/CAD>. Acesso em: 5 abr. 2017.

Antropologia e/da Educação no Brasil: Entrevista com Neusa Gusmão. Cadernos de Campo, n. 22, p. 147-160, 2013. São Paulo: EdUSP, 2013.

. Formação de Professores de Ciências Sociais ante às Políticas Educacionais. Crítica e Sociedade: revista de cultura política, Uberlândia, v. 3, n. 1, p. 132-152, 2013b. Disponível em: <http://www.seer.ufu.br/index.php/criticasociedade/article/view/23425>. Acesso em: 5 abr. 2017.

- O lugar da Antropologia na formação docente: um olhar a partir das escolas normais. Pró-Posições, Campinas, v. 24, n. 2, p. 27-40, 2013c. Disponível em: $<$ http://www.scielo.br/scielo.php?script=sci_arttext\&pid=S0103-73072013000200003\&lng=pt\& nrm=iso\&tlng=pt>. Acesso em: 5 abr. 2017.

. Revisitando a História do Ensino de Sociologia na Educação Básica. Acta Scientiarum. Education, Maringá, v. 35, n. 2, p. 179-189, 2013d. Disponível em: <http://periodicos.uem.br/ojs/index.php/ActaSciEduc/article/view/20222>. Acesso em: 5 abr. 2017.

Sobre o Lugar da Educação na Antropologia Brasileira. Temas em Educação, João Pessoa, v. 24, n. 1, p. 1-12, 2015. Disponível em: <http://periodicos.ufpb.br/ojs2/index.php/rteo/article/viewFile/21395/13578>. Acesso em: 5 abr. 2017. 
OLIVEIRA, A.; BOIN, F.; BÚRIGO, B. D. A Antropologia, os Antropólogos e a Educação no Brasil. Revista Anthropológicas, Recife, v. 27, n. 2, p. 21-44, 2016.

PEIRANO, Mariza. A antropologia como ciência social no Brasil. Etnográfica, Lisboa, Portugal,

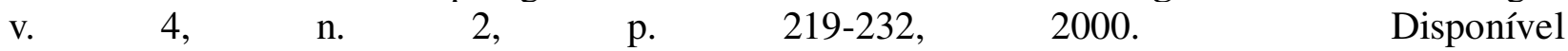
em:<http://ceas.iscte.pt/etnografica/docs/vol_04/N2/Vol_iv_N2_219-232.pdf $>$. Acesso: 5 abr. 2017.

RUBIM, C. R. Antropólogos Brasileiros e a Antropologia no Brasil: A Era da Pós-Graduação. 1996. 486f. Tese (Doutorado em Ciências Sociais) - Universidade Estadual de Campinas, Campinas, 1996.

SARTORI, A. J. A experiência como mediadora no ensino da antropologia para quem não vai ser antropólogo. 2010. 400f. Tese (Doutorado em Antropologia) - Universidade Federal de Santa Catarina, Florianópolis, 2010.

SCHWEIG, G. R. Aprendizagem e ciência no ensino de sociologia na escola: um olhar desde a antropologia. 2015. 175f. Tese (Doutorado em Antropologia) - Universidade Federal do Rio Grande do Sul, Porto Alegre, 2015.

SINISI, L., CERLETTI, L.; RÚA, M. La enseñanza de la Antropología y la formación de profesores. Revista Espacios de crítica y producción, s/v, n. 46, 2011, pp. 94-101.

WEBER, S. O Professorado e o Papel da Educação Na Sociedade. Campinas: Papirus, 1996. 
Teacher Training for Teaching Anthropology in Brazil and Argentina

\begin{abstract}
Anthropology became systematized as a science in the nineteenth century, and its first teachers were self-taught, and it was initially only taught at a university level, although some countries had limited experiences with Anthropology in basic education. This article analyzes the education of anthropology teachers in Brazil and Argentina, considering the various institutional and academic settings in both countries. While Argentina has fewer courses than Brazil, these courses are more specific, and focused on the education of anthropology teachers. In Brazil anthropology is offered within social science courses in basic education, and specifically within sociology classes. This paper analyzes how teacher courses in Anthropology education in these two countries deal with the challenges in their different institutional and academic contexts.
\end{abstract}

Keywords: Anthropology education. Education of Anthropology Teachers. Anthropology and Education.

\section{Amurabi Pareira de Oliveira}

E-mail:amurabi_cs@hotmail.com

Maximiliano Rúa

E-mail: maximilianorua@gmail.com
Formación de Docentes en la Enseñanza de Antropología en Brasil y Argentina

\section{Resumen}

La antropología como ciencia ha sido sistematizada a partir del siglo XIX, de manera que sus primeros maestros fueron autodidactas en esta área del conocimiento, y aunque su enseñanza se limitaba inicialmente a la educación universitaria, en algunos países también hubo las experiencias específicas en la Educación Básica. Este artículo se ocupa de la formación de profesores para la enseñanza de Antropología en Brasil y Argentina, teniendo en cuenta los diversos contextos institucionales y académicos existentes en ambos países, ya que, por un lado, en Argentina hay menos Profesorados en comparación con Brasil, por el otro, estos cursos son más específicos para la formación de profesores en Antropología mientras que en Brasil esta formación se disuelve en los cursos de Ciencias Sociales, con su enseñanza estipulada para la Sociología que existe en la Educación Básica. En el presente artículo buscamos analizar como los cursos de formación del profesorado para la Enseñanza de Antropología en las escuelas en esos dos países trabajan los desafíos en sus diferentes contextos institucionales y académicos.

Palabras clave: Enseñanza de Antropología. Formación Profesores de Antropología. Antropología y Educación.

Enviado em: 29/05/2015

Aprovado em: 05/09/2016 